\title{
Spotlight on vismodegib in the treatment of basal cell carcinoma: an evidence-based review of its place in therapy
}

This article was published in the following Dove Press journal:

Clinical, Cosmetic and Investigational Dermatology

10 May 2017

Number of times this article has been viewed

\section{Zoe Apalla' \\ Chrysoula Papageorgiou' \\ Aimilios Lallas' \\ Elena Sotiriou' \\ Elizabeth Lazaridou' \\ Efstratios Vakirlis ${ }^{\prime}$ \\ Athanassios Kyrgidis ${ }^{2}$ \\ Demetrios loannides'}

'First Department of Dermatology, Aristotle University, ${ }^{2}$ Department of Oral and Maxillofacial Surgery, Faculty of Dentistry, Aristotle University, Thessaloniki, Greece
Correspondence: Zoe Apalla First Department of Dermatology, Aristotle University, 124 Delfon str. 54643, Thessaloniki, Greece

Tel +302313308882

Fax +302310850762

Email zoimd@yahoo.gr
Abstract: Vismodegib is approved for the treatment of adult patients with metastatic ( $\mathrm{mBCC})$ or locally advanced basal cell carcinoma (laBCC) that have recurred following surgery or for those who are not good candidates for surgery (risk/benefit ratio is against patient's benefit, either because of the general condition or because of the expected morbidity from the surgery) or radiation therapy. This article provides an evidence-based review of its current place in therapy. Analytically, the clinical implications in the management of laBCCs and $\mathrm{mBCCs}$ and possible new indications, including the neoadjuvant use before surgical excision, are discussed, while in the end, the challenges regarding class-related adverse events and their optimal management are highlighted.

Keywords: vismodegib, sonic hedgehog inhibitors, basal cell carcinoma, treatment, review

\section{Introduction}

Basal cell carcinoma (BCC) is the most common type of skin cancer accounting for $\sim 70 \%-80 \%$ of nonmelanoma skin cancers. Current evidence suggests that BCC arises from basal keratinocytes of the interfollicular epidermis or the hair follicles. ${ }^{1,2}$ Initially, it spreads in the epidermis and superficial dermis and, if neglected, it invades locally, leading to significant tissue destruction. Overactivation of sonic hedgehog $(\mathrm{SHH})$ signaling plays a key role for the induction of BCC through the inhibition of a transmembrane protein called PTCH or the activation of a transmembrane protein called SMO. ${ }^{3}$ Subsequently, various interactions are triggered, leading eventually to gene transcription and BCC development. From an epidemiological point of view, a male predilection is recorded, with male-to-female ratio increasing with age. ${ }^{3}$ The relationship between exposure to ultraviolet (UV) radiation and the risk of BCC is complex, but it seems that a history of excessive sun exposure in childhood and adolescence contributes in its development. ${ }^{4}$ In addition to UV exposure, light skin phototype, radiation therapy, immunosuppression, and genetic syndromes also represent significant predisposing factors. ${ }^{3}$ It has been demonstrated that a personal history of a $\mathrm{BCC}$ represents a major risk factor for the development of a second one later in life. ${ }^{5}$ According to the National Comprehensive Cancer Network (NCCN) guidelines, $30 \%-50 \%$ of patients with BCC will develop a second one within 5 years from the initial diagnosis. ${ }^{6}$

Surgical excision remains the gold standard of treatment for the majority of BCCs. However, depending on the histological subtype, tumor characteristics, and patient's physical profile, other therapeutic options may be considered, namely imiquimod, photodynamic therapy, cryosurgery, curettage, and radiotherapy. ${ }^{3}$ 
Vismodegib is a recently introduced SHH pathway inhibitor. Its efficacy was evaluated in the ERIVANCE study in individuals with "advanced BCC" (aBCC). The term aBCC refers to locally advanced $\mathrm{BCC}$ (laBCC) and symptomatic metastatic $\mathrm{BCC}(\mathrm{mBCC})$. Although a precise definition of laBCC is not available, the term is used to describe "inoperable" BCCs or tumors whose excision would result in unacceptable functional impairment. A BCC might be "inoperable" because of the following factors, alone or combined: exceedingly large size, problematic localization, and recurrence. $\mathrm{mBCC}$ metastasizes to the regional lymph nodes or to distant organs, such as the lungs and the bones. $\mathrm{mBCC}$ is extremely rare, with an incidence ranging from $0.003 \%$ to $0.1 \%$ of all BCCs. ${ }^{3}$ Based on the findings of the ERIVANCE study, vismodegib was approved in January 2012 in the USA and 1.5 years later in Europe for the treatment of aBCC in adults.

The aim of this manuscript was to review the most important literature data on vismodegib, outline its current position in real-life practice in terms of efficacy and drug-related toxicity, and highlight certain challenges regarding its use, including the expansion of the indication and management of adverse events (AEs).

\section{Pre-marketing studies Pilot studies}

The first available data for the treatment of aBCC with hedgehog pathway inhibitors were drawn from an openlabel Phase I clinical trial conducted by Von Hoff et al. ${ }^{7}$ The authors confirmed the implication of hedgehog pathway in BCC pathogenesis and suggested that its inhibition could be beneficial in treating inoperable tumors. Thirty-three patients were enrolled in the study, 18 (55\%) with metastatic disease and $15(45 \%)$ with laBCC. Seventeen patients received 150 $\mathrm{mg} /$ day of GDC-0449 (small molecule targeting the hedgehog pathway - vismodegib), 15 received $270 \mathrm{mg}$ /day, and 1 received $540 \mathrm{mg} /$ day. The overall response rate was $50 \%$ and $60 \%$ for $\mathrm{mBCC}$ and $\mathrm{laBCC}$, respectively. The median duration of response was 8.8 months. The final results from this clinical trial report an overall response rate (complete and partial responses) of $58 \%$ ( 19 of 33 patients) for laBCC with a median duration of response of 12.8 months. ${ }^{8}$ Fatigue, muscle spasms, alopecia, dysgeusia, and nausea were the most common AEs, noted in $30 \%$ of the patients. Furthermore, increasing the dose from 150 to $270 \mathrm{mg}$ was shown not to result in higher drug plasma levels.

Following these findings, LoRusso et $\mathrm{al}^{9}$ evaluated the optimal vismodegib dose and frequency of dosing. Adminis- tration of $150 \mathrm{mg}$ of the drug once daily was suggested as the optimal dose to achieve sufficient efficacy in BCC patients. This therapeutic scheme was well tolerated, with AEs of similar incidence and severity to those of less frequent dosing.

\section{ERIVANCE study}

In the ERIVANCE BCC study, ${ }^{10}$ a multinational, multicenter, nonrandomized, 2-cohort study, the efficacy and safety of vismodegib were assessed in 104 patients with histologically confirmed aBCC. Participants received oral vismodegib 150 mg once daily until disease progression, intolerable toxicity, or discontinuation of the study. The primary end point (objective response rates [ORRs], meaning complete or partial response, determined by an independent evaluator) was seen in $30 \%$ of the patients with $\mathrm{mBCC}$ (partial response) and in $43 \%$ of the patients with laBCC (complete and partial response). The median response duration was 7.6 months in both cohorts. The most commonly reported AEs included muscle spasms, alopecia, dysgeusia, weight loss, fatigue, nausea, decrease in appetite, and diarrhea and occurred in at least $20 \%$ of all participants. Twenty-six patients $(25 \%)$ reported serious AEs, while fatal AEs were recorded in 7 patients. However, the latter were not attributed to the drug. The results of the additional 12-month follow-up confirmed the findings of the primary analysis concerning AEs. ${ }^{11}$ Interestingly, amenorrhea was observed in 2 of 6 women of childbearing potential, a finding that is in accordance with other studies (see the "STEVIE study" section). Moreover, it was shown that these AEs most commonly occurred within the first 6 months of treatment and the risk decreased thereafter.

Regarding the efficacy data of the 12-month report, the ORR determined by independent external evaluators slightly increased in both laBCC and $\mathrm{mBCC}$ cohorts. In addition, the median response duration remained stable for $\mathrm{MBCC}$, while it increased from 7.6 to 9.5 months for laBCC. Finally, it was reported that $72.1 \%$ of all patients discontinued the treatment, with the most frequent reason for discontinuation being patient's decision (23.1\%), followed by progression of the disease (21.2\%) and AEs (17.3\%). The 18-, 24-, and 30-month updates of the pivotal ERIVANCE study were consistent with the results of primary analysis. ${ }^{12-14}$ The ORR remained stable until the end of the 30-month follow-up period for both $\mathrm{mBCC}$ and laBCC. Moreover, the median duration of response was 14.8 months for $\mathrm{mBCC}$ and 26.2 months for laBCC in the final update (compared with 12.9 and 7.6 months in the primary analysis, respectively). Furthermore, the same AEs were observed during the 30 -month period. It is noteworthy that, in the 30-month update, only 9 patients 
were still on treatment, while 69 patients were in survival follow-up. The ORR and the median duration of response during the 30 -month period are summarized in Table 1.

\section{EAS study}

Subsequent to the ERIVANCE trial, another open-label, 2-cohort study (EAS) investigated the effect of vismodegib in $120 \mathrm{BCC}$ patients. ${ }^{15}$ The researchers stated that the results of the study were similar to those of ERIVANCE, although different methodology was stratified to assess the response to treatment. Specifically, while in ERIVANCE, the evaluation of response was performed both by the investigators and by independent reviewers, in EAS it was conducted only by one investigator. However, the authors of EAS study compared their results to the results of the independent review of the ERIVANCE trial. In efficacy-evaluable patients $(\mathrm{n}=95)$, ORR was $46.4 \%$ and $30.8 \%$ for $\mathrm{laBCC}$ and $\mathrm{mBCC}$, respectively, with a median time to response of 2.6 months for both cohorts. The main limitation of the study is the short treatment phase (5.5 months) due to early termination requested by the sponsor, after the US Food and Drug Administration approval. Regarding the safety results, the most common AEs were similar to those found in ERIVANCE and occurred in $>15 \%$ of the patients. In an attempt to correlate clinical factors with better outcome, the history of previous systemic therapy for laBCC was predictive of a poorer response.

A pooled analysis from ERIVANCE and EAS studies demonstrated a similar efficacy of vismodegib for laBCC in patients with and without basal cell carcinoma nevus syndrome (BCCNS). ${ }^{16}$
An additional analysis investigated the safety and efficacy of vismodegib in 2 different age groups, retrieving again data from ERIVANCE and EAS studies. ${ }^{17}$ The analysis revealed comparable safety and efficacy of vismodegib in patients aged $<65$ years and $>65$ years.

\section{STEVIE study}

STEVIE was a multicentric, open-label trial, designed to assess the safety of once-daily dose of $150 \mathrm{mg}$ vismodegib in $468(94 \%)$ individuals with laBCC and 31 (6\%) individuals with mBCC. ${ }^{18}$ In total, 400 patients $(80 \%)$ discontinued treatment, and the major reasons were AEs, disease progression, and patient's request. Ninety-eight percent of the patients experienced at least one AE. The most common AEs were muscle spasms, alopecia, dysgeusia, weight loss, asthenia, decreased appetite, ageusia, diarrhea, nausea, and fatigue. The aforementioned AEs represented reasons for treatment discontinuation. The majority of AEs were grade 1-2 (mildto-moderate), with only $22 \%$ of participants experiencing serious AEs, such as general health deterioration and development of squamous cell carcinoma (SCC). It is important to underline the development of irregular menses or amenorrhea in 8 of $29(28 \%)$ women of childbearing potential, since this $\mathrm{AE}$ that may raise concerns about the use of vismodegib in this particular population. Moreover, 31 deaths were recorded, 21 of which were attributed to AEs. However, only 2 of them were potentially related to vismodegib. Finally, the researchers investigated the correlation between the incidence of AEs and the duration of drug exposure. Based on their findings, they concluded that long-term exposure ( $\geq 12$ months)

Table I ORRs and median DOR in the primary analysis and the 12-month, the 18-month, the 24-month, and the 30-month follow-up of ERIVANCE BCC study ${ }^{14}$ as they are assessed by an IRF and an investigator review

\begin{tabular}{|c|c|c|c|c|c|c|c|c|}
\hline \multirow[t]{2}{*}{$\mathrm{N}=104$} & \multicolumn{2}{|c|}{$\begin{array}{l}\text { IRF-assessed } \\
\text { ORR } \\
\end{array}$} & \multicolumn{2}{|c|}{$\begin{array}{l}\text { Investigator- } \\
\text { assessed ORR }\end{array}$} & \multicolumn{2}{|c|}{$\begin{array}{l}\text { Median DOR } \\
\text { (IRF) (months) }\end{array}$} & \multicolumn{2}{|c|}{$\begin{array}{l}\text { Median DOR } \\
\text { (investigator) (months) }\end{array}$} \\
\hline & $\mathrm{mBCC}$ & laBCC & $\mathrm{mBCC}$ & laBCC & $\mathrm{mBCC}$ & laBCC & $\mathrm{mBCC}$ & laBCC \\
\hline $\begin{array}{l}\text { Primary analysis } \\
\text { - SOT: } 51\end{array}$ & $30 \%$ & $43 \%$ & $45 \%$ & $60 \%$ & 7.6 & 7.6 & 12.9 & 7.6 \\
\hline $\begin{array}{l}\text { I2-month update } \\
\text { - SOT: } 29 \\
\text { - NM }\end{array}$ & $33.3 \%$ & $47.6 \%$ & $48.5 \%$ & $60.3 \%$ & 7.6 & 9.5 & 14.7 & NE-SR \\
\hline $\begin{array}{l}\text { I8-month update } \\
\text { - SOT: } 2 \text { I } \\
\text { - ISFU: } 56\end{array}$ & - & - & $48.5 \%$ & $60.3 \%$ & - & - & 14.7 & 20.3 \\
\hline $\begin{array}{l}\text { 24-month update } \\
\text { - SOT: I4 } \\
\text { - ISFU: } 63\end{array}$ & - & - & $48.5 \%$ & $60.3 \%$ & - & - & 14.8 & 26.2 \\
\hline $\begin{array}{l}\text { 30-month update } \\
\text { - SOT: } 9 \\
\text { - ISFU: } 69\end{array}$ & - & - & $48.5 \%$ & $60.3 \%$ & - & - & 14.8 & 26.2 \\
\hline
\end{tabular}

Abbreviations: BCC, basal cell carcinoma; DOR, duration of response; IRF, independent review facility; ISFU, in survival follow-up; laBCC, locally advanced basal cell carcinoma; $\mathrm{mBCC}$, metastatic basal cell carcinoma; NE-SR, not estimable-still responding; NM, not mentioned; ORR, objective response rates; SOT, still on treatment. 
increases the incidence of AEs, but these are mainly of mild or moderate severity.

With respect to response rates, ORR was $66.7 \%$ for patients with laBCC and $37.9 \%$ for those with $\mathrm{mBCC}$. The median duration of response was 22.7 and 10 months for the patients with laBCC and $\mathrm{mBCC}$, respectively.

Summarizing the results of STEVIE, it seems to keep up with those of ERIVANCE study, despite the fact that different methods were used to assess the response in terms of efficacy.

Investigator-assessed ORR and median duration of response (DOR) of the three major clinical trials (ERIVANCE, EAS, and STEVIE) are summarized in Table 2.

\section{Studies on BCCNS}

In addition to the aforementioned post hoc analysis using data from ERIVANCE and EAS, ${ }^{16}$ the efficacy of vismodegib in patients with BCCNS was evaluated by Tang et al ${ }^{19,20}$ in a multicenter, randomized, double-blind, placebo-controlled, Phase II trial. The study found a satisfactory efficacy of vismodegib, based on the shrinkage of the preexisting tumors and the reduction of mean rate of new BCCs that required surgical resection. Moreover, new surgically eligible BCCs were less frequent even after discontinuation of the treatment. Interestingly, re-introduction of vismodegib resulted in reduction in size and number in most carcinomas, suggesting low resistance rate in patients with BCCNS. Finally, the majority of AEs were mild or moderate and included alopecia, muscle cramps, dysgeusia, and weight loss.

\section{Post-marketing studies}

Almost 4 years after receiving conditional approval, numerous post-marketing studies evaluated vismodegib in reallife scenarios, as well as in possibly beneficial off-label indications.

A major concern of the treatment with vismodegib includes histologic clearance of the lesions and subsequent durability of outcome. Sofen et al conducted a study to evaluate the beneficial effect of vismodegib in patients with

Table 2 ORRs and median DOR of the three major clinical trials about vismodegib

\begin{tabular}{llllc}
\hline \multicolumn{2}{l}{ Investigator-assessed ORR } & & \multicolumn{2}{l}{$\begin{array}{l}\text { Investigator-assessed } \\
\text { median DOR (months) }\end{array}$} \\
\hline Study & mBCC & laBCC & mBCC & laBCC \\
\hline ERIVANCE $^{14}$ & $48.5 \%$ & $60.3 \%$ & 14.8 & 26.2 \\
EAS $^{15}$ & $30.8 \%$ & $46.4 \%$ & $\begin{array}{l}\text { Not estimable short median } \\
\text { duration of treatment }\end{array}$ \\
STEVIE $^{18}$ & $37.9 \%$ & $66.7 \%$ & 10 & 22.7 \\
\hline
\end{tabular}

Abbreviations: DOR, duration of response; laBCC, locally advanced basal cell carcinoma; $\mathrm{mBCC}$, metastatic basal cell carcinoma; ORR, objective response rates. operable BCCs by measuring the rate and durability of complete histologic clearance (CHC). ${ }^{21}$ Efficacy and safety were tested, too. This was a multicentric, nonrandomized, 3-cohort, open-label, Phase II study, in which a total of 74 patients were enrolled. In the first group, CHC rate was assessed after 12 weeks of treatment. The second group received a 12 -week treatment course and durability of $\mathrm{CHC}$ was evaluated after a 24-week observation period, while, in the third group, a 8 weeks on/4 weeks off/8 weeks on therapeutic schema was administered in order to assess improved tolerability. Histologic evaluation was performed after Mohs surgery. $\mathrm{CHC}$ rate was $42 \%, 16 \%$, and $44 \%$ in cohorts 1,2 , and 3 , respectively. As the study hypothesis was that the $\mathrm{CHC}$ rate would be $>50 \%,>30 \%$, and $>50 \%$ for the cohorts, respectively, it did not achieve its primary end point. Concerning AE, almost all of the patients developed at least one, with the most common (muscle spasms, alopecia, dysgeusia, and ageusia), occurring in $\geq 30 \%$ of participants. Severe AEs were recorded in 6 patients $(8 \%)$, and most of them were considered to be unrelated to active treatment except from one hepatitis case, which resolved after drug discontinuation.

Viscusi et $\mathrm{al}^{22}$ recently published real-life data regarding the use of vismodegib in laBCC, focusing on efficacy, tolerability, and outcome after treatment cessation. The outcome was defined as complete clinical response (CCR), partial clinical response (PCR), stable disease, or progression, and the evaluation was performed in the first follow-up visit after treatment discontinuation. In the case of complete response (CR), disease-free survival (DFS, time interval between vismodegib cessation and last available follow-up, death, or recurrence) was recorded. A total of 31 laBCCs were included in the study. Fifty-five percent (17/31) and 42\% (13/31) of the tumors achieved CCR and PCR, respectively. One lesion (3\%) remained stable, and none $(0 \%)$ of the lesions progressed during treatment. In the group of PCR, the mean size reduction of the tumor was $52 \%$ (range 11\%-80\%). The DFS ranged from 2 to 21 months (mean DFS 9.3 months) at the time of data cut-off for all cases. Interestingly, only 2 individuals (8\%) discontinued treatment due to drug-related AEs. Nine of 31 tumors were recurrent. Among the 22 nonrecurrent laBCCs, there were 14 (64\%) that achieved CCR. Two of 5 patients that received a second therapeutic course demonstrated CCR. However, the neoplasms eventually recurred 12 and 74 weeks after the end of the first treatment course. A patient with PCR that further improved with retreatment (65\%-79\% tumor shrinkage) finally was treated successfully with Mohs micrographic surgery. The latter approach gains appreciation among physicians, since tumor shrinkage after 
short-term use of vismodegib makes the surgical excision feasible. Concerning AE, dysgeusia (65\%), muscle cramps (60\%), fatigue (35\%), weight loss (40\%), and alopecia (60\%) were the most often reported. Except alopecia, all the others were transient and resolved 3 months after cessation of vismodegib. One patient developed an in situ SCC within the treated field after reaching CCR. There were 6 deaths during treatment or during follow-up, but none of them was related to vismodegib.

As reported above, an interesting indication of vismodegib might include its short-term use as a neoadjuvant (pre-operatively) to surgery for high-risk, large but operable BCCs, in an effort to decrease morbidity and preserve vital structures. Based on this rationale, Kwon et al ${ }^{23,24}$ conducted an open-label, single-arm trial. Eleven individuals with at least $1 \mathrm{BCC}$ (>5 $\mathrm{mm}$ in diameter) received vismodegib for $4 \pm 2$ months. With the use of a software program, the investigators were able to define the surgical defect if the patient would not receive vismodegib and compare it with the surgical defect after neoadjuvant vismodegib. Neoadjuvant treatment with vismodegib decreased the size of the final surgical defect by $34.8 \%$ compared with baseline and allowed clearance of the neoplasm with an average of two Mohs stages. After a mean follow-up of 11.5 months, only 1 tumor recurred, while after a longer period of $\sim 22$ months (range 12-28 months), no further recurrences were seen.

These promising results provide additional support for the pre-operative use of vismodegib as a neoadjuvant to surgery in order to reduce surgery-associated morbidity and possible deformities. This is particularly relevant when dealing with large, or located in cosmetic sensitive areas, high-risk BCCs.

Periocular and orbital areas represent a sensitive anatomic location, not always feasible for surgical approach. Efficacy of vismodegib as an alternative therapeutic option for periocular and orbital BCCs was assessed in one prospective and one retrospective case series. ${ }^{25}$ In the former study, 12 patients with orbital or periocular laBCC underwent treatment with vismodegib. Overall, treatment resulted in complete and partial response in 3 and 6 patients, respectively, while 3 were stable at the last follow-up. Two individuals progressed after complete response for 38 months and stable disease for 16 months, respectively. All participants developed grade I drug-related adverse effects, while 5 patients developed grade II adverse effects. Taking into account the significant clinical response in most patients and the manageable AEs, the authors consider vismodegib as beneficial for this particular indication.

In the second study, ${ }^{26} 7$ patients with orbital or periocular $\mathrm{BCCs}$ that met the criteria for vismodegib received the drug for a mean of 11 weeks (range, 4-16 weeks), while the mean duration of follow-up was 7.3 months (range, 5-10 months). Two individuals (29\%) achieved CCR, 2 (29\%) achieved $>80 \%$ PCR, $2(29 \%)$ achieved $<35 \%$ partial clinical regression, and $1(14 \%)$ progressed. AEs occurred in 6 patients (86\%), with alopecia (29\%), dysgeusia (29\%), muscle cramps (29\%), and anorexia (14\%) being the most common. Of note, 2 participants (29\%) developed new SCC (keratoacanthoma type) at uninvolved sites. The latter $\mathrm{AE}$ has been reported in various studies and has triggered some debates about the risk and benefit and the cautions of vismodegib use in patients with history of SCC and/or risk factors for SCC.

\section{Vismodegib and risk for SCC}

The possibility of development of SCC at distant sites or within the primary tumor bed during or after treatment with vismodegib has triggered some recent debates in the literature. ${ }^{27}$ Based on the results of a case-control study, in which an increased risk for SCC in patients treated with vismodegib was recorded, the authors recommended continued skin surveillance after the initiation of vismodegib. ${ }^{28}$ However, the latter study received harsh criticism concerning its methodology, and its results were strongly disputed. ${ }^{29,30}$ The question whether patients undergoing treatment with vismodegib are in increased risk for development of SCC and if this AE is clinically significant needs to be further elucidated.

\section{Prevention and management of vismodegib-associated $A E$}

One of the major limitations in the use of SHH pathway inhibitors is the class effect AE. Although the severity of AEs in the majority of the studies was low to medium, their persistence throughout the long-term treatment courses caused significant morbidity and influenced the quality of life. Interruption, and/or eventual discontinuation of treatment, which may affect the clinical outcome, was not unusual. Evidence shows that most of these AEs are mechanistically associated to inhibition of SHH pathway. SHH signaling plays an important role in regulation of injury-induced angiogenesis and myogenesis, while it is also involved in the integrity of taste function and regulation of growth cycle of the hair follicle. Many investigators are working toward the development of mechanism-based preventive and management strategies that will allow physicians appropriate counseling and adequate interventions in order to preserve a high quality of life and an optimal benefit from treatment. Detailed evaluation of comorbidities (eg, alopecia, myopathies) and concomitant medication that may result in cumulative intolerance prior 
to treatment is highly recommended. Patients' awareness and education about preventive efforts (eg, adequate hydration, passive stretching, gentle physical activity) is also a part of the management strategy. Analytically, apart from nonpharmacological interventions, for grade 1-2 muscle spasms, they recommend calcium channel blockers, diltiazem, verapamil, sports drinks (electrolytes supplements), and gabapentin or pregabalin. Magnesium supplementation, even though very popular, provided only mild relief in patients suffering from idiopathic cramping. In the case of muscle spasms $>$ grade 3, 2- to 4-week treatment interruption should be considered. Regarding dysgeusia and ageusia, marinating meat, spicy food, cooling foods, and adding sweet ingredients to meat were shown to be helpful. Lacouture et al, ${ }^{31}$ based on their experience, suggest using new recipes, eating candy before meal, cutting food with lemon, and many other nonpharmacological advices. Recovery of gustation is expected at least 4 weeks from vismodegib discontinuation. In a pilot study of delta-9-tetrahydrocannabinol versus placebo in dysgeusia, participants from the former group experienced improved chemosensory perception, food taste, appetite, and calorie consumption. Supportive care for vismodegib-associated alopecia includes treatment of comorbidities that may synergistically deteriorate the problem. Vismodegib-induced nausea can be prevented by the use of serotonin inhibitors, especially when initiated before vismodegib and continued daily. Table 3 summarizes the recommended strategies for the management of the most important AE.

In an effort to further balance activity and toxicity, two long-term intermittent dosing regimens in patients with multiple BCCs were assessed. Indeed, based on the findings of MIKIE study, intermittent schemes improved overall tolerability without compromising the activity of vismodegib. In this scenario, short-term treatment interruptions may limit the number of patients that discontinue treatment due to $\mathrm{AE}$, while retaining efficacy outcome. ${ }^{32}$

Table 3 Etiopathogenesis and recommended management of the main treatment-related $A E s$ from vismodegib

\begin{tabular}{lll}
\hline AE & Etiopathogenesis & Management \\
\hline Alopecia & $\downarrow$ Dermal papillae function/hair & Minoxidil 5\% \\
& growth & b.i.d. \\
Ageusia/dysgeusia & $\downarrow$ Bitter/sweet responsivity & Nutrition \\
& Taste buds & consult \\
Muscle spasms & $\downarrow$ Myogenic factors & Amlodipine \\
& Injury recovery & 10 mg/day \\
Weight loss & $\downarrow$ Glucose uptake in muscle/ & Nutrition \\
& brown adipocytes & consult \\
\hline
\end{tabular}

Abbreviations: AEs, adverse events; b.i.d., twice a day.

\section{Conclusion}

SHH inhibitors represent the only pharmacologic agents to have proven efficacy in this indication. Vismodegib can be considered a revolutionary drug, since it fulfilled (at least to some extent) the previously unmet need of managing patients with mBCC or laBCC. After its approval in 2012, the efficacy and safety profile of the drug have been strongly corroborated, while studies reporting on real-life data indicate a trend of clinicians to expand the indications for vismodegib administration to less advanced tumors.

There are two main challenges for the future: The evaluation of the use of vismodegib as a neoadjuvant treatment and the development of strategies to better manage the drugrelated AEs. "Drug holiday" might represent an effective strategy to increase drug tolerability and minimize treatment withdrawals. However, it remains to be further elucidated if intermittent regimens retain a similar efficacy as compared with the continuous dosage scheme.

\section{Disclosure}

The authors report no conflicts of interest in this work.

\section{References}

1. Youssef KK, Van Keymeulen A, Lapouge G, et al. Identification of the cell lineage at the origin of basal cell carcinoma. Nat Cell Biol. 2010;12(3):299-305.

2. Wang GY, Wang J, Mancianti ML, Epstein EH Jr. Basal cell carcinomas arise from hair follicle stem cells in Ptch1(+/-) mice. Cancer Cell. 2011;19(1):114-124.

3. Marzuka AG, Book SE. Basal cell carcinoma: pathogenesis, epidemiology, clinical features, diagnosis, histopathology, and management. Yale J Biol Med. 2015;88(2):167-179.

4. Gallagher RP, Hill GB, Bajdik CD, et al. Sunlight exposure, pigmentary factors, and risk of nonmelanocytic skin cancer. I. Basal cell carcinoma. Arch Dermatol. 1995;131(2):157-163.

5. Marcil I, Stern RS. Risk of developing a subsequent nonmelanoma skin cancer in patients with a history of nonmelanoma skin cancer: a critical review of the literature and meta-analysis. Arch Dermatol. 2000; 136(12):1524-1530.

6. National Comprehensive Cancer Network. NCCN Clinical Practice Guidelines in Oncology: Basal Cell Skin Cancer, Version 1.2015. NCCN. Available from: https://www.nccn.org/store/login/login. aspx?ReturnURL=https:/www.nccn.org/professionals/physician_gls/ pdf/nmsc.pdf. Accessed January 26, 2016.

7. Von Hoff DD, LoRusso PM, Rudin CM, et al. Inhibition of the hedgehog pathway in advanced basal-cell carcinoma. $N$ Engl J Med. 2009; 361(12):1164-1172.

8. LoRusso PM, Rudin CM, Reddy JC, et al. Phase I trial of hedgehog pathway inhibitor vismodegib (GDC-0449) in patients with refractory, locally advanced or metastatic solid tumors. Clin Cancer Res. 2011;17(8):2502-2511.

9. LoRusso PM, Jimeno A, Dy G, et al. Pharmacokinetic dose-scheduling study of hedgehog pathway inhibitor vismodegib (GDC-0449) in patients with locally advanced or metastatic solid tumors. Clin Cancer Res. 2011;17(17):5774-5782.

10. Sekulic A, Migden MR, Oro AE, et al. Efficacy and safety of vismodegib in advanced basal-cell carcinoma. N Engl J Med. 2012;366(23): 2171-2179. 
11. Sekulic A, Migden MR, Lewis K, et al. Pivotal ERIVANCE basal cell carcinoma (BCC) study: 12-month update of efficacy and safety of vismodegib in advanced BCC. J Am Acad Dermatol. 2015;72(6):10211026.e8.

12. Sekulic A, Migden MR, Basset-Seguin N, et al. Long-term safety and efficacy of vismodegib in patients with advanced basal cell carcinoma (aBCC): 18-month update of the pivotal ERIVANCE BCC study. J Clin Oncol. 2013;31(Suppl):abstr 9037.

13. Sekulic A, Migden MR, Oro A, et al. Long-term safety and efficacy of vismodegib in patients with advanced basal cell carcinoma (BCC): 24-month update of the pivotal ERIVANCE BCC study. Poster presented at: 22nd EADV Congress; October 2-6, 2013; Istanbul, Turkey.

14. Sekulic A, Migden MR, Basset-Seguin N, et al. Long-term safety and efficacy of vismodegib in patients with advanced basal cell carcinoma: Final update (30-month) of the pivotal ERIVANCE BCC study. J Clin Oncol. 2014;32:5s(Suppl; abstr 9013).

15. Chang AL, Solomon JA, Hainsworth JD, et al. Expanded access study of patients with advanced basal cell carcinoma treated with the hedgehog pathway inhibitor, vismodegib. JAm Acad Dermatol. 2014;70(1):60-69.

16. Chang AL, Arron ST, Migden MR, et al. Safety and efficacy of vismodegib in patients with basal cell carcinoma nevus syndrome: pooled analysis of two trials. Orphanet J Rare Dis. 2016;11(1):120.

17. Chang AL, Lewis KD, Arron ST, et al. Safety and efficacy of vismodegib in patients aged $\geq 65$ years with advanced basal cell carcinoma. Oncotarget. 2016;7(46):76118-76124.

18. Basset-Seguin N, Hauschild A, Grob JJ, et al. Vismodegib in patients with advanced basal cell carcinoma (STEVIE): a pre-planned interim analysis of an international, open-label trial. Lancet Oncol. 2015;16(6):729-736.

19. Tang JY, Mackay-Wiggan JM, Aszterbaum M, et al. Inhibiting the hedgehog pathway in patients with the basal-cell nevus syndrome. $N$ Engl J Med. 2012;366(23):2180-2188.

20. Tang JY, Ally MS, Chanana AM, et al. Inhibition of the hedgehog pathway in patients with basal-cell nevus syndrome: final results from the multicentre, randomised, double-blind, placebo-controlled, phase 2 trial. Lancet Oncol. 2016;17(12):1720-1731.

21. Sofen H, Gross KG, Goldberg LH, et al. A phase II, multicenter, openlabel, 3-cohort trial evaluating the efficacy and safety of vismodegib in operable basal cell carcinoma. J Am Acad Dermatol. 2015;73(1):99-105.
22. Viscusi KS, Hanke CW. Vismodegib for locally advanced basal cell carcinoma: descriptive analysis of a case series and comparison to the literature. J Drugs Dermatol. 2015;14(9):956-962.

23. Ally MS, Aasi S1, Wysong A, et al. An investigator-initiated openlabel clinical trial of vismodegib as a neoadjuvant to surgery for high-risk basal cell carcinoma. J Am Acad Dermatol. 2014;71(5): 904-911.

24. Kwon GP, Ally MS, Bailey-Healy I, et al. Update to an open-label clinical trial of vismodegib as neoadjuvant before surgery for high-risk basal cell carcinoma (BCC). J Am Acad Dermatol. 2016;75(1):213-215.

25. Ozgur OK, Yin V, Chou E, et al. Hedgehog pathway inhibition for locally advanced periocular basal cell carcinoma and basal cell nevus syndrome. Am J Ophthalmol. 2015;160(2):220-227.

26. Gill HS, Moscato EE, Chang AL, Soon S, Silkiss RZ. Vismodegib for periocular and orbital basal cell carcinoma. JAMA Ophthalmol. 2013; 131(12):1591-1594.

27. Alarcon I, Pasquali P, Malvehy J, Puig S. Tumor regrowth and development of keratinocytic neoplasms in patients under smoothened inhibition: in vivo assessment with reflectance confocal microscopy. Skin Res Technol. Epub 2016 Oct 27.

28. Mohan SV, Chang J, Li S, Henry AS, Wood DJ, Chang AL. Increased risk of cutaneous squamous cell carcinoma after vismodegib therapy for basal cell carcinoma. JAMA Dermatol. 2016;152(5):527-532.

29. Gjersvik P. Study on the risk of cutaneous squamous cell carcinoma after vismodegib therapy for basal cell carcinoma: not a case-control study. JAMA Dermatol. 2016;152(10):1172.

30. Puig S, Sampogna F, Tejera-Vaquerizo A. Study on the risk of cutaneous squamous cell carcinoma after vismodegib therapy for basal cell carcinoma: not a case-control study. JAMA Dermatol. 2016;152(10): $1172-1173$.

31. Lacouture ME, Dréno B, Ascierto PA, et al. Characterization and management of hedgehog pathway inhibitor-related adverse events in patients with advanced basal cell carcinoma. Oncologist. 2016; 21(10):1218-1229.

32. Dreno B, Kunstfeld R, Hauschild A, et al. Two intermittent vismodegib dosing regimens in patients with multiple basal-cell carcinomas (MIKIE): a randomised, regimen-controlled, double-blind, phase 2 trial. Lancet Oncol. 2017;18(3):404-412.
Clinical, Cosmetic and Investigational Dermatology

\section{Publish your work in this journal}

Clinical, Cosmetic and Investigational Dermatology is an international, peer-reviewed, open access, online journal that focuses on the latest clinical and experimental research in all aspects of skin disease and cosmetic interventions. This journal is included on PubMed. The manuscript management system is completely online
Dovepress

and includes a very quick and fair peer-review system, which is all easy to use. Visit http://www.dovepress.com/testimonials.php to read real quotes from published authors 